\title{
Establishing an Institutional Framework for an E-learning Implementation - Experiences from the University of Rijeka, Croatia
}

\author{
Marta Zuvic-Butorac, Zoran Nebic, and Damir Nemcanin \\ University of Rijeka, Faculty of Engineering, Rijeka, Croatia
}

martaz@riteh.hr; znebic@riteh.hr; dnemcanin@riteh.hr

\author{
Tonci Mikac, and Pero Lucin \\ University of Rijeka, President's Office, Rijeka, Croatia
}

tmikac@riteh.hr; ured@uniri.hr

\section{Executive Summary}

Faced with the need of transforming the university structure, processes, and programs according to the Bologna reform, and in order to become more flexible and more responsive to the environment, the University of Rijeka management decided to enable e-learning implementation as an institutional, strategically planned operation. The manuscript describes the three years long process of building an implementation framework for the use of information and communication technology (ICT) in teaching and learning in the form of blended e-learning - combined classroom and online learning via e-learning platform (or learning management system, LMS).

The implementation started practically from ground zero, with the goal of preparing the infrastructure and the environment for the implementation, while also building a community of educated practitioners. A few points for getting support and networking have been established within the university infrastructure: faculty e-learning teams and/or representatives taking care of the institutional promotion and deployment of e-learning and connected to the university Committee for e-learning as a policy making body, the e-learning centre, which provides e-learning platform (LMS) maintenance, development, and technical user's support, and the IT Academy which assures delivery and development of education from general ICT to specialized e-learning programs. All the processes and activities within the network are assured for quality control.

Two years after the deployment, the platform hosts more than 400 e-courses with 15,000 estudents. The survey among teachers using e-learning to perform blended courses revealed satisfaction and general acceptance, indicating the increase in effectiveness of teaching and learning processes.

Material published as part of this publication, either on-line or in print, is copyrighted by the Informing Science Institute. Permission to make digital or paper copy of part or all of these works for personal or classroom use is granted without fee provided that the copies are not made or distributed for profit or commercial advantage AND that copies 1) bear this notice in full and 2) give the full citation on the first page. It is permissible to abstract these works so long as credit is given. To copy in all other cases or to republish or to post on a server or to redistribute to lists requires specific permission and payment of a fee. Contact HPublisher@InformingScience.orgH to request redistribution permission.
Although much of the effort and investing into resources is still needed, we believe that the report presented here could serve as a case of good practice in institutionally supported e-learning implementation. With the institutionally planned approach, we succeeded in building a solid institutional framework, awareness and understanding, visibility, promotion, and common language 
within the community, which will all hopefully serve for future progress.

Keywords: E-learning in higher education, Bologna process, management reform, countryspecific developments, improving classroom teaching, strategic planning

\section{Introduction}

Faced with the need of transforming the university structure, processes, and programs according to the Bologna reform, and in order to become more flexible and more responsive to the environment, the University of Rijeka management decided to enable e-learning implementation as an institutional, strategically planned operation. The manuscript describes the three years long process of building an implementation framework for the use of information and communication technology (ICT) in teaching and learning in the form of blended e-learning - combined classroom and online learning via e-learning platform (or learning management system, LMS).

The University of Rijeka is one of the seven universities in Croatia, middle-sized with respect to number of students $(\approx 17,500)$ and academics $(\approx 1,100)$. The University consists of fourteen constituent institutions - faculties, departments, an academy of arts, a library, and a student's centre. It was formally founded in 1973, although the origins of higher education (HE) in this area date back to the $17^{\text {th }}$ century.

The organizational structure of the University, being very much the same for all the universities in the country, has many problems. Universities are still struggling with the traditional system of education and are in need of fundamental changes, especially concerning governance. The higher education system in our region represents a mixture of a standard, inherited system and numerous decentralized policies and institutional frameworks established in the period after the Croatian War of Independence (1991-1995). Universities have a historically grown, non-integrated structure, where faculties are legal entities, leading to the current situation where a university functions just as a weak alliance of its constituent parts. Within such a non-integrated institution, the president's office does not have any significant managerial competencies because these lie exclusively with the faculties.

Since the beginning of the decade, the University of Rijeka has put many efforts toward a functionally integrated institution, with much more empowerment of the central university bodies and centralized services. Those processes were greatly supported by participation in various EU funded projects, such as Tempus, Framework Projects, Jean Monnet, Interreg, and CEEPUS, through which the University managed to build the competencies and organize specialized university offices. During the same period, as the University was (in 2003) granted the former military property of 37 ha for the purpose of building a university campus, the president's office faced an even greater need to start the integration, reorganization of governance and university management and implementation of the strategic management principles in all the segments of everyday practice. In this light, the University has published the Strategy of University of Rijeka 2007-2013, the first such policy document adopted among Croatian HE institutions. The Strategy strongly defined the university's mission and vision, objectives, and tasks with corresponding action plans and methodologies for follow-up.

The University of Rijeka envisions its profile as a research oriented university geared toward sustainable development with high quality and strong performance in outcome-based and lifelong teaching and learning. The educational part of the vision was specifically elaborated through the Strategy for e-learning implementation at the University of Rijeka, and this document (again the first such policy document in Croatia) became an integral part of the university strategy.

To increase the efficiency of the university services related to teaching and learning (T\&L) and to improve its overall quality, these specific strategic objectives were set up: to increase the effi- 
ciency of studying, to modernize curricula and syllabi in the context of the Bologna declaration, to ensure the compatibility with international educational systems, to improve quality of teaching and learning through implementation of learning-outcomes oriented curricula, to increase the inter-university and international cooperation, to enhance the student and teacher mobility, and to improve student services. In order to start all the processes needed to reach the above mentioned objectives, implementation of e-learning as an institutionally supported and strategically planned operation seemed the right approach. Introducing blended e-learning (Bonk \& Graham, 2006) could help achieve higher quality and efficiency of campus teaching and learning, but could also help attract more students, reaching new target groups of students and achieving better flexibility of the teaching and learning process.

Within this framework, the extensive reforms of study programs' curricula have been made. As the main outcome of this process the University expected not only to achieve standards of academic degrees and quality assurance comparable and compatible with other European universities but also to improve students' performance and enable them to gain degrees faster. Moreover, the centralized service of e-learning support and distributed e-learning network were viewed as important elements of future integrated university support systems.

In this paper, we will describe the efforts put in implementation of e-learning in the teaching and learning process at University as an institutional strategically planned operation and report on the progress achieved so far.

\section{Methods and Context}

The driving force for entering the adventure of e-learning implementation was the current state of low efficiency and effectiveness of teaching. The statistical data suggested that only $30 \%$ students eventually complete their studies and it takes them 1.5 to 2 times the expected normal length of studies. This current state was also marked with very poor use of information and communication technology (ICT) in teaching and learning, in spite of having good infrastructure and equipment: we have had broadband Internet access for several years (Croatian academic and research network, CARNet) connecting all the member institutions, teachers have had PCs at their disposal for their personal use (almost at 100\%), and the number of students owning a PC and having broadband access at home was approaching 95\%. However, according to the results of the survey among teachers on use of ICT in T\&L at the University in 2005 (not published), the most frequent form of ICT use was limited to PowerPoint presentations in the classroom and publishing them on the course web pages.

Another key driver, equally important, was the Bologna process and the need to redefine the complete curriculum by using precise definitions of learning outcomes for all the teaching and learning done at the University. E-learning implementation was a good opportunity to do two things at the same time - redefinition of curriculum according to the Bologna process and pursuing the change in most of the formal teaching practice, which could be enhanced by introducing more of technology into traditional T\&L. Both processes were always centered on overall improvement of quality of T\&L practice. Improvement of quality was mostly seen through exploring the possibilities of widening and strengthening the communication between teachers and students through blended e-courses, as well as implementing the concept of constant follow-up of every student through the course activities. According to the newly adopted University book of rules on undergraduate studies, students acquire $70 \%$ of their grade during the course and $30 \%$ at the final exam. In this light, the need for communicating with students and continuous assessment of their work and progress during the course becomes imperative. Institutionally supported elearning implementation and institutionally supported capacity building for e-learning seemed the right approach, as suggested by Bates (1999) and more recently by Davis and Fill (2007) and Azcel, Peake, and Hardy (2008). 
Participation in the Tempus project UM-JEP 19105-2004 Education quality improvement by elearning technology (EQIBELT) (http://equibelt.srce.hr) helped our University not only to build competencies and capacities in e-learning with a high level of professionalism but also to improve quality assurance. The Strategy for e-learning implementation has been reached as an important outcome of this project, and it was delivered in October 2006 by the University of Rijeka as the first such document in Croatia. The corresponding action plan was set and approved by the University Senate in October 2007, including allocated resources and defined financial instruments for implementation of activities in 2008 and subsequent period. The project activities of the University were coordinated through the University Information Technology Academy (IT Academy), which took over many of the activities from the action plan to be realized. The partnership in Tempus EQIBELT also provided financial means to setup the new ICT classroom within IT Academy facilities.

The strategy defined specific objectives to be achieved during the implementation process are to build the awareness and understanding of the concept of e-learning, to build institutional support in technical terms (single, open source-based learning management system, LMS, fully customizable to specific needs, and with an in-house support ), to build support in terms of providing education for the use of e-learning that is both high quality and low in training time, to provide funding and establish an award for e-learning on the university level, to build a community of practitioners, and to provide a reliable institutional framework, not only as a central isolated service but also as distributed network with variety of points/services where one can get help. The strategy also suggested developing the quality control processes, especially in the terms of assessing the efficiency and the effectiveness of T\&L supported by e-learning. By the end of January 2010 we had finished the initial survey among teaching staff deploying blended e-learning and the results are presented here: a wide survey aimed at students using blended e-courses, which will assess the acceptance, satisfaction and attitudes on e-learning is in preparation.

\section{Results}

\section{Institutional Implementation - Processes and Outcomes}

Here we present the results achieved during three years of working on the institutionally supported e-learning implementation at the University of Rijeka. The activities were organized through a strategically planned operation and the corresponding results will be presented with respect to operational phases and their outcomes.

The initial phase had the objective of increasing the awareness and understanding of e-learning as well as building ICT competencies at the University. It included setting up a variety of educational programs for ICT at the IT Academy, organizing events for promoting good e-learning practices, and writing and submitting the Strategy for e-learning implementation to the University Senate.

The education was organized by the IT Academy, which delivers yearly on average 2,500 hours of specialized lifelong learning education to the academic community. The education covered programs for acquiring general ICT skills and literacy (use of office desktop applications and Internet), graphical design skills (image editing, graphic design and desktop publishing), and specialized programs for IT professionals (system administrators and engineers, web developers).

Promotional events were organized, comprising of short seminars in the form of guest lectures on e-learning, performed by members of the Croatian academic community having experience with online teaching and learning. The events took place on the faculties willing to host the event, and, depending on the institution's governance culture, the attendance was sometimes obligatory for teaching staff. Thematically, the seminars were specifically tailored to the audience, for example, 
an e-learning promotion on Faculty of Engineering was held by an e-learning practitioner teaching fluid mechanics. Those short seminars gave the academics the opportunity to gain some insight into the possibilities and advantages of online collaboration with students, offered by the use of an LMS.

The participation of our University in the aforementioned Tempus EQIBELT project acquainted a group of academics from the University of Rijeka with e-learning infrastructure and management in EU higher education institutions having respectable backgrounds in e-learning deployment. This helped to recognize the good practices that could be adopted or adapted to our specific environment and culture, as well as to indicate practices that should be avoided in implementation. Having acquired this knowledge, the appointed workgroup produced the initial document, the Strategy for e-learning implementation at the University of Rijeka, which was presented to the whole University community and, after minor corrections, adopted by the University Senate. This document was a key white paper that assured the process continuation.

There were two important outcomes of the first phase: first, the academic community became aware of e-learning as a new way to approach the teaching practice, and second, the University management accepted the long-term policy document towards implementation of e-learning. As the activities specified in the e-learning strategy were parts of the University Strategy, they were now budgeted through annual action plans, which was of the highest importance for further actions.

The next phase included the organizational and functional setup of the University of Rijeka elearning net (Figure 1), which was considered to be the main sustainability factor of the process. Activities included setting up new university bodies (such as faculty e-learning teams and the university Committee for e-learning), offering a new educational program on e-learning use for teaching staff, and establishing the University e-learning centre as a central point for e-learning support.

Faculty teams were generally formed as groups of early technology adopters at each institution. The e-learning commissionaire at the institution also acts as a University Committee member, thus establishing the connection from an institutional to the university level. The main task of faculty teams is to promote good practice in their own institutions, provide direct contact with users (both teachers and students), and report annually to the university Committee.

IT Academy designed and offered the education on e-learning use for teaching staff with the set of 3 modules that comprised altogether 26 hours of classroom training and approximately 40 hours of online teaching and learning on how to organize, design, develop, deliver, and manage a pedagogically sound blended e-learning course. In the first, shortest module, "Why e-learning and how can it improve my teaching practice?" participants took the student's role and studied foundations of e-learning (history, modes of implementation, advantages and disadvantages, basic features, new teaching opportunities with e-learning, technical prerequisites, etc.), with the aim of challenging every participant to rethink his/hers T\&L in the light of using e-learning tools that could help his or her students achieve learning outcomes more efficiently. The participants were obliged to build a structural map for the new e-course (implementation of specific e-learning tools in the existing course structure). The second module, "Multimedia tools for producing e-content," treated different available applications for creating and editing multimedia elements and their adequacy for inclusion in e-courses. The learning outcome for this module was to personally create a piece of multimedia content that was related to the participant's existing teaching practice. In the third module, "How to set up an e-course using Moodle?" the participants got to know the LMS as a course designer and a tutor and learnt how to manage the contents and the course administration and how to plan the course and course delivery. This module also included the presentation of the new e-literature services of the University library (developed through activities 
based on the University e-learning strategy) helping teachers to get and organize digital course literature.

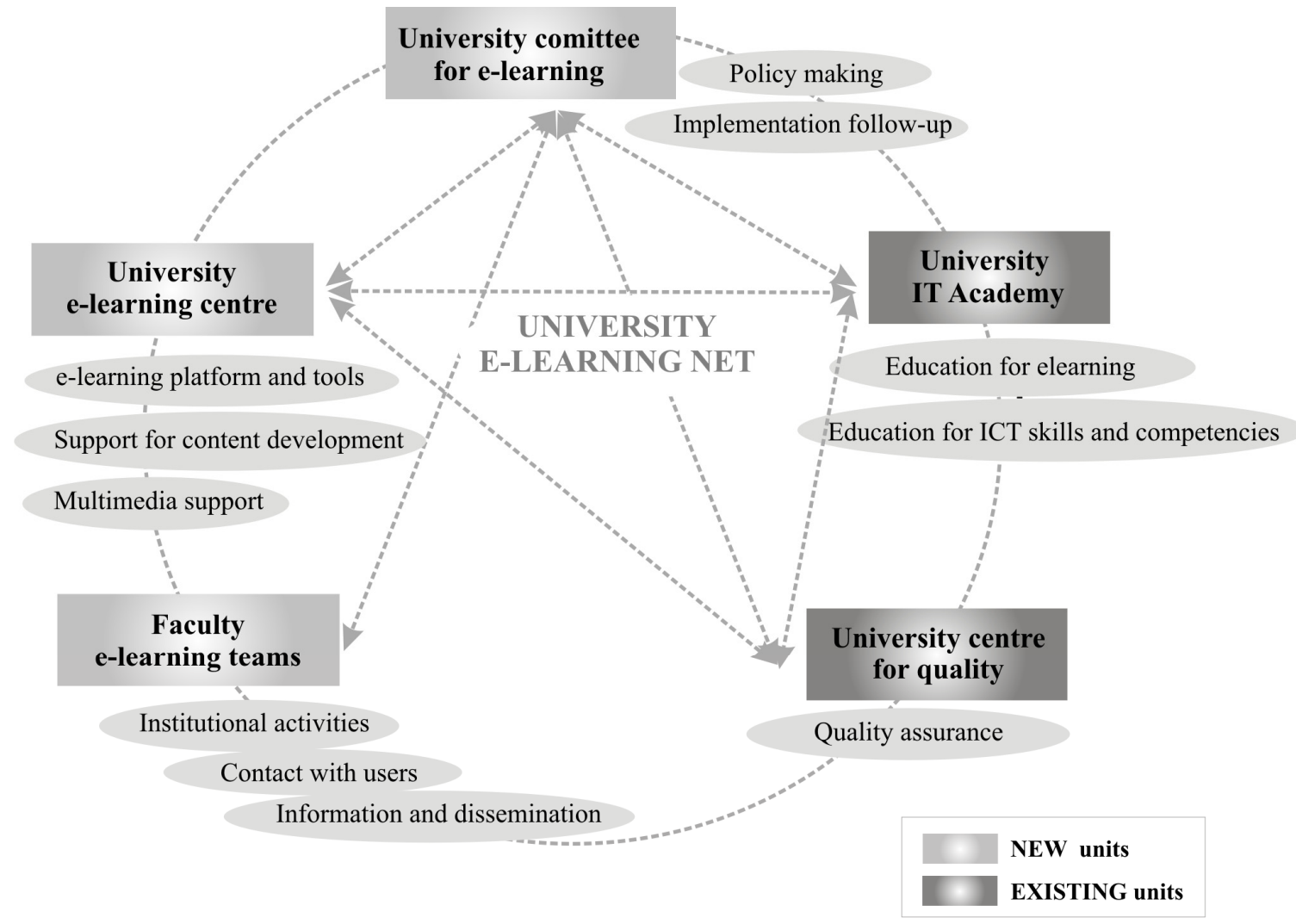

Figure 1. E-learning net design at the University of Rijeka. Presented are functional elements (institutions, centers, and groups), their main responsibilities and connections to other elements of the net.

Since the beginning of 2008, there are 110 participants in the program who received training in elearning theory and practical implementation. As the attendees satisfaction surveys indicated, the participants were enthusiastic about getting to know new teaching and learning tools with which they can experiment in their teaching practice and about possibilities to improve their student's learning outcomes. They assessed the program and its delivery with very high grades regarding the quality of teaching and learning, the range and quality of content, the quality of organization and classroom adequacy, as well as technical support. Worth noticing is an important collateral outcome of this activity - the educational program gathered academics interested in problems of improving higher education teaching and learning and thus initiated the creation of a new community of e-learning practitioners. Face-to-face sessions during the program enabled mingling of academics where they have had a chance to get to know each other, to share experiences and discuss problems.

The University Committee for e-learning implementation, established as a policy making and follow-up group, in one of its first tasks, delivered a document on recommendations for e-course content development. The document provided definitions of specific e-learning tools and elements to be included e-courses, suggestions on course content structuring and use of multimedia, and suggestions on copyright issues for accessible material on the web. The document also set the 
classification of e-courses with respect to the level of e-learning implementation into 4 classes, in order to enable easier institutional benchmarking of e-learning.

The University e-learning centre was established following the acceptance of an action plan for setting up the Centre together with negotiating (with the University management) for full-timeequivalent (FTE) positions and facilities. Facilities were housed within IT Academy rooms at the Faculty of Engineering, while one FTE academic position was approved starting January 2009. As its first task, the centre has set up the university platform for e-courses based on the Moodle LMS. The new platform was named MudRI (after Moodle and University of Rijeka), meaning wise in Croatian, so an owl was selected for the symbolic representation in the logotype. Current development of MudRI platform includes adjustments to the specific needs required by the new Book of rules for studies at the University of Rijeka, in order to support the follow up and assessment of students' performance during the course. Future development seeks for the integration with other ICT supported student services in the domain of evidence of enrollments and student's achievements. New functionality has been established recently, the MudRI TV, an add-on to our platform that enables recording and video management of the lectures and seminars. Also the specialized education for the use of new modules (grading and assessment, MudRI TV) are organized and offered to the community of practitioners.

In the domain of further development and strengthening of the e-learning community of practitioners, we started with the organization of an Annual University e-day, the first one being held in November 2009, as the joint meeting of all e-learning practitioners at the University. During autumn 2009, the University Committee also organized the first University competition for the best blended e-course and at this occasion awarded the best blended e-learning course taught on the University for the past academic year.

Summing up the results presented on institutionally supported e-learning implementation in our University teaching and learning practice, we must emphasize that not everything was seamless and frictionless in the process.

Since there were no resources to organize technical support for our LMS from the very beginning, the collaboration with the already existing Centre for e-learning at the University of Zagreb (CEU Zagreb) was established in order to provide the platform for testing, developing, and delivery of e-courses from University of Rijeka. Presently, we still have e-courses from University of Rijeka active on CEU Zagreb's platform and have to invest our efforts in marketing for the migration to our platform.

The educational program for teachers intending to use e-learning has lived through a few adjustments following the suggestions of participants, particularly in the number of hours per module. Additionally, as we establish new functionalities on our e-learning platform, some topics in the program change as well, so we need to offer the original participants refresher training.

As far as institutional participation is concerned, not all of the faculties participated from the beginning (e.g., Medical School, Faculty of Tourism and Hospitality Management, Faculty of Maritime Studies), but as the process went on they are now trying to catch up. Lack of participation was due to the faculties having different information systems (IS), but the situation has been resolved with a university policy requiring all faculties to use the same IS. This way we expect them to join the e-learning implementation process more easily. Functional adjustments of our elearning platform for following-up and assessment of students, as well as establishing the integration with IS, are posing a new driving force for their inclusion and participation. But the resistance to change is still present, since all the parties involved need to employ a lot of resources in setting up the new infrastructure, as well as to change their usual practices. 
Our near-future plans include the integration of the IT Academy and the University e-learning centre into a new Centre for teaching and learning support. The centre would be responsible for providing education, as well as pedagogical and technical support (especially in the domain of multimedia), for all the T\&L done at the University. With the university campus area being in its final stages of construction of buildings and infrastructure for all the common university services and four faculties, the newly formed Centre will be located in the new facilities. As far as new services are concerned, there is a specific task for the university library in organization and setting up of a new librarian service, specifically oriented to support the design of e-courses. The service will include selection, acquisition, digitalization, storage, and cataloguing and linking of e-references, with the aim of helping the course designer in building a digital reference collection. The service will be given on an individual request basis, to a registered e-course designer. Expected outcome of this near-future phase is a functionally implemented university e-learning system with assured continuous follow up and quality control, possibly partially integrated with other ICT supported services, and a growing community of e-learning practitioners seeking a better T\&L quality.

\section{E-learning Quality Assessment by Teaching Staff}

The overall efforts described previously resulted in 413 active e-courses offered to $15500 \mathrm{e}$ students of University of Rijeka by October 2010 (Figure 2). It should be noted that the number of e-students is the number of students enrolled in all e-courses, therefore one student in person is multiplied as e-student by the number of e-courses she/he has enrolled.

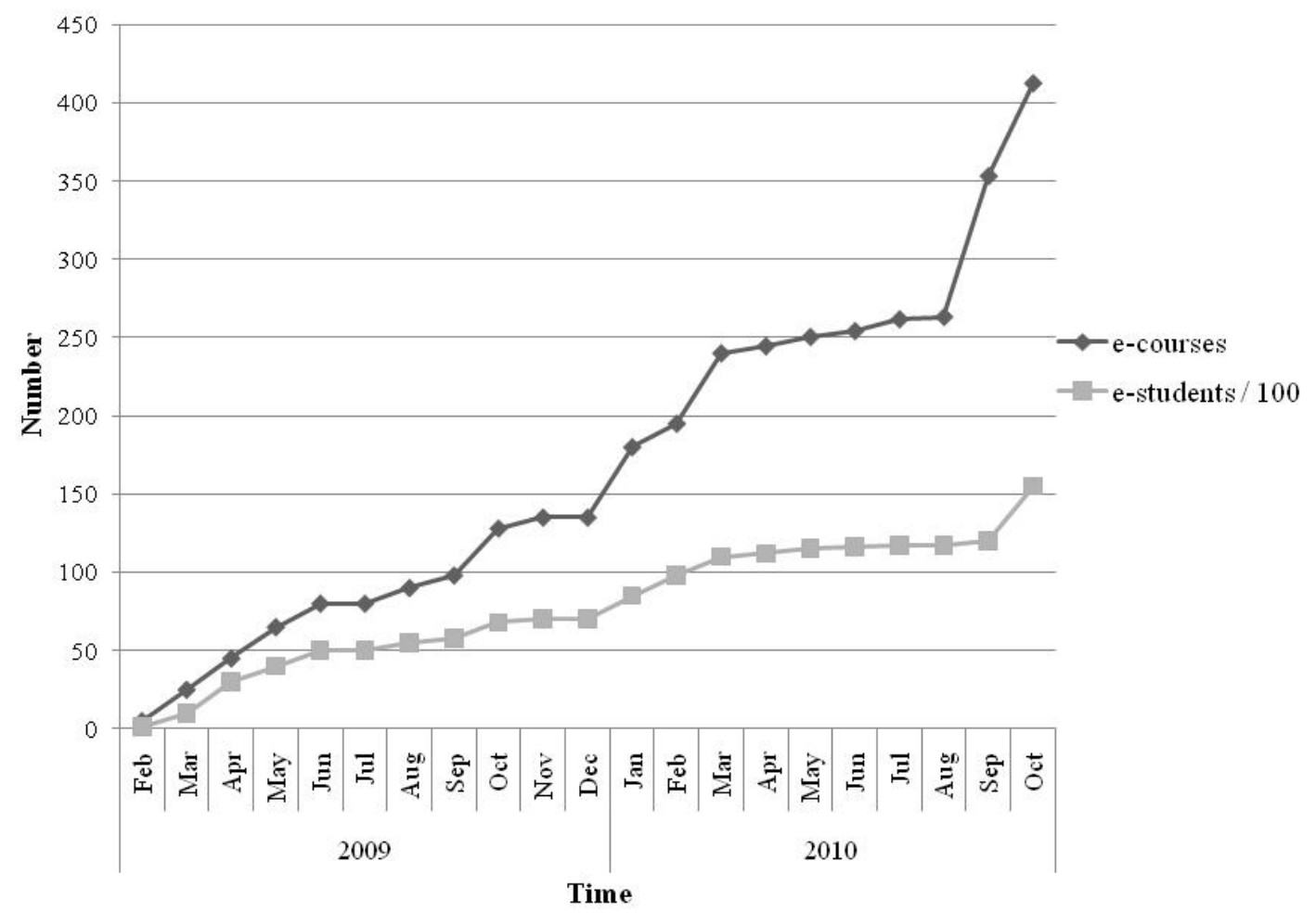

Figure 2. Number of activated e-courses and e-students since the beginning of the university e-learning platform (MudRI) use.

Even though the increase in the number of activated e-courses is still under way, we think that the most important present task is quality control and assessment of e-learning at the University. In 
this context, we performed a preliminary survey among the academics offering blended e-courses to students through our LMS at the beginning of 2010. The survey intended to produce some quantitative and qualitative indicators on effectiveness and efficiency of e-learning. Teachers were asked to provide certain numerical data (number of students enrolled and successfully finished, average grade) to self-evaluate their course (presence and completeness of all relevant course materials, regularity of communication with students, implementation of self-assessment tests, giving feedback to students through e-course), to estimate the benefits of e-courses in planning, organization, delivery, and administration of teaching, to judge possible impact of elearning use on IT literacy (personal and student's), to assess the e-learning acceptance by students, and to judge whether the student's success during the course improved with respect to noe-learning implemented.

We have collected 79 filled questionnaires (out of possible 209 at the time) so the overall response rate was $38 \%$. Every questionnaire reported on one e-course and was categorized with respect to the area of study: 1) engineering, mathematics and life science, 2) information technology, and 3) social sciences, arts, and humanities. This type of categorization helped to achieve almost equally distributed percentage of answers across categories. Although engineering, math, and science courses prevail in the structure of e-courses present on our platform, the highest response rate was obtained among social science and humanities teachers (Table 1.).

Table 1. General data on surveyed e-courses and comparisons across different subject areas

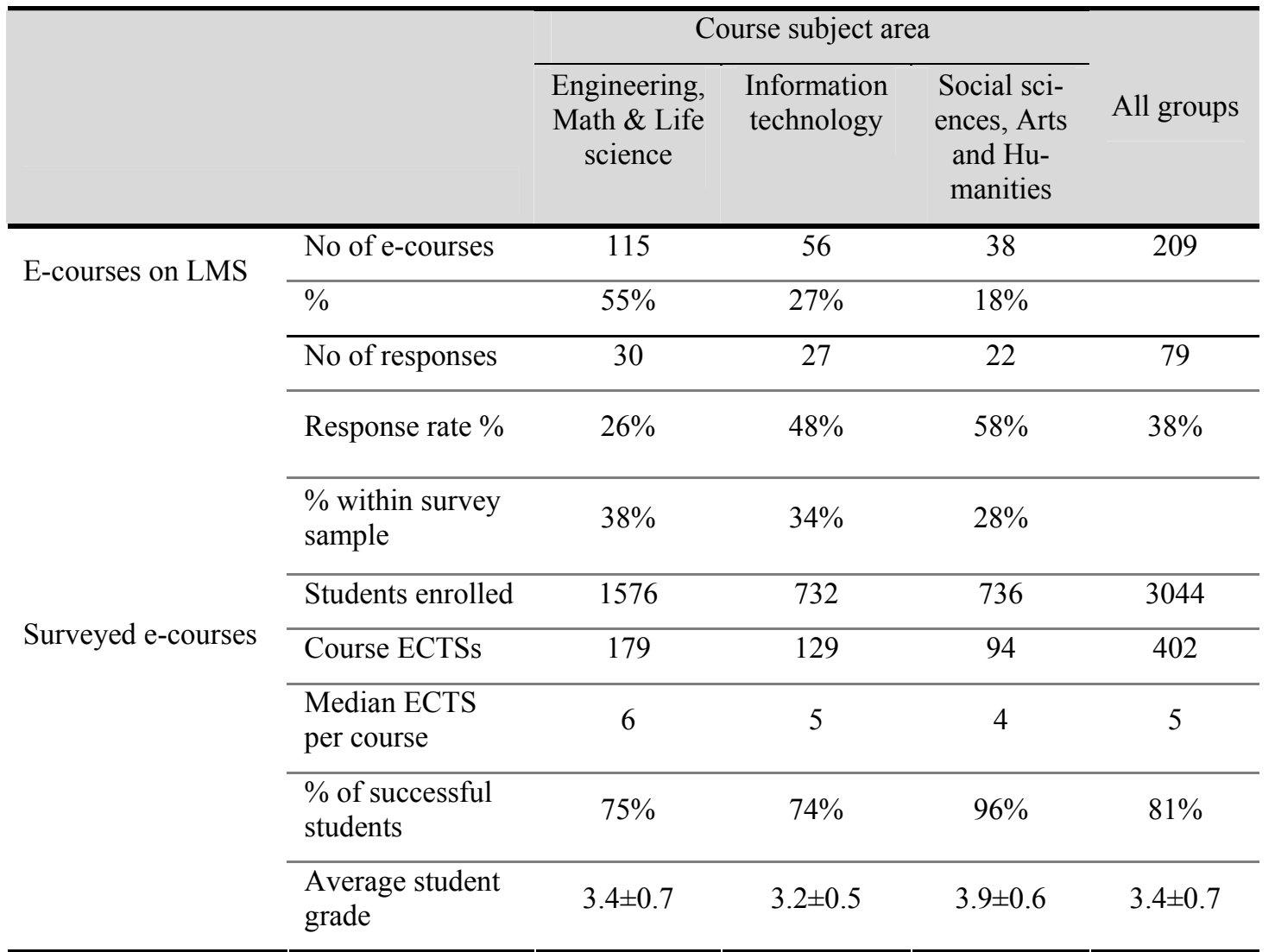

Surveyed e-courses enrolled 3044 students and on average $81 \%$ of students successfully completed the course. As most of the curricula changed with respect to course content, organization and student obligations concurrently with e-learning deployment, no valid correspondence to pre- 
vious success scores could be established. As it can be seen from the general course description data, the social science, arts, and humanities courses present themselves with significantly higher percentage of successful students (difference of proportions test, $\mathrm{p}=0.009$ ), higher numerical grades achieved (analysis of variance, $\mathrm{p}=0.004$ ), and significantly lower number of European Credit Transfer System (ECTS) points per course (Kruskal-Wallis test, $\mathrm{p}=0.001$ ). ECTS points measure the workload students need in order to achieve expected learning outcomes.

Teachers were further asked to provide the data on basic elements of e-courses (presence and completeness of materials, communication tools, self-evaluation tests, and feedback provided to students, Table 2, Q1-Q6), to self reflect on benefits of organizing an blended e-course (Table 2, Q7-Q10) and to judge students' acceptance, students' participation and efficacy in achieving learning outcomes (Table 2, Q11-Q14).

The state of the e-learning elements deployed in surveyed e-courses is satisfactory - the vast majority has all of the course content materials present, communication with students implemented and practiced regularly, as well as the feedback to students on their work provided. Those data do not differ with respect to course subject (Table 2, Q1-Q4, Fisher exact test, $\mathrm{p}>0.05$ ). The selfevaluation tests for students are present only in $23 \%$ of courses and the significantly lowest percentage of $4 \%$ is reported for IT courses (Table 2, Q5, Fisher exact test, $\mathrm{p}=0.007$ ).

Around $92 \%$ of teachers claim that the LMS is helping them in organization of course materials, management of course delivery, and the course administration. These positive statements are equally high in percentage across all categories of course subjects (Table 2, Q7-Q9, Fisher exact test, $\mathrm{p}>0.05$ ).

\section{Table 2. Survey questions and comparisons of teachers' answers} across different course subject areas

\begin{tabular}{llcc}
\hline & & Answer & \multirow{2}{*}{ YES } \\
Question & $97 \%$ & 0,202 \\
\hline Q2 & Is the majority of course content presented on the LMS? & $90 \%$ & 0,297 \\
Q3 & Is the communication with students implemented? & $99 \%$ & 0,280 \\
Q4 & Is the communication regular? & $95 \%$ & 0,092 \\
Q5 & Does the e-course have student self-evaluation tests implemented? & $23 \%$ & 0,007 \\
Q6 & Do students get feedback on their work through e-course? & $84 \%$ & 0,677 \\
Q7 & Is the LMS helping you to manage the delivery of course? & $92 \%$ & 0,195 \\
Q8 & Is the LMS helping you to organize course materials better? & $92 \%$ & 0,195 \\
Q9 & Is course administration easier with the LMS? & $91 \%$ & 0,195 \\
Q10 & Is your information literacy improved due to e-learning? & $60 \%$ & $<0,001$ \\
Q11 & Is the information literacy of your students improved due to the & & \\
& use of e-learning? & $87 \%$ & 0,260 \\
Q12 & Do your students accept e-learning willingly? & $96 \%$ & 0,019 \\
Q13 & Do they participate as expected? & $83 \%$ & 0,008 \\
Q14 & Are your students more successful in achieving learning outcomes & & \\
& due to use of the e-course? & $48 \%$ & 0,013 \\
\hline
\end{tabular}

$* p$ is a level of statistical significance calculated from generalized Fisher exact test on $3 \times 2$ contingency tables (answers across course subject categories); tested was a null hypothesis, being the frequencies of answers yes are equally distributed across course subject categories (engineering, math and life sciences, information technology and social sciences and humanities); for $p<0.05$ distributions are considered significantly different across course subject categories. 
Interestingly, $60 \%$ of teachers do think that their IT literacy has improved by the use of elearning, and significant deviation is found only for the IT teaching staff that reports no change in their IT literacy due to e-learning use (Table 2, Q10, Fisher exact test, $\mathrm{p}<0.001$ ). As the students' IT literacy is concerned, the $87 \%$ of teachers judge it to be improved, irrespective of the course subject category (Table 2, Q11, Fisher exact test, $\mathrm{p}=0.260$ ). Acceptance of blended e-learning among students is estimated as high as $96 \%$, and the reported unacceptance comes exclusively from the social sciences and humanities (Table 2, Q12, Fisher exact test, $\mathrm{p}=0.019)$. Students' participation in e-learning is "as expected by the teacher" in $83 \%$ of reports, with significantly higher percentage of positive answers (100\%) coming from IT category of course subjects (Table 2, Q13, Fisher exact test, $\mathrm{p}=0.008)$. As far as the estimation of T\&L efficacy is concerned, $48 \%$ of teachers claim their students to be more successful than in previous times, $21 \%$ answered negatively, and $32 \%$ were indecisive because of overall change in study program and course curriculum (Table 2, Q14). However, there were 15 reports which provided data on previous success scores and compared numbers show some improvements (successful course completion rate increased by $8 \%$ ), although not statistically significant.

Asked to comment on their positive experiences with e-learning, teachers point out the benefits of course contents accessibility for the students, improved communication with students, easy manageable continuous student's assessment and more effective teaching and learning time management. Additionally they stress the importance of having the educational support as well as having continuous support during the course development, testing, and delivery phase. Many of them express that e-learning experience facilitated the change toward positive attitude on new T\&L methodologies, especially in the domain of ICT use in T\&L. One comment stated "After just one year of having it, I can't imagine my teaching without the e-part anymore!"

However, there were also remarks on negative aspects of e-learning implementation in practice. Very often the academic expressed the frustration from the situation of unequal teachers' practices - some teachers invest in building blended e-learning courses, while others do not even communicate with students by e-mail. They also point out to difficulties they experienced with different levels of ICT skills and literacy among students, specifically in the student population on humanistic and social sciences. Very often they also find the new T\&L situation more demanding, not only as a additional workload during the preparation of materials and activities, but also during the course, where (especially in the case of large groups of students) the communication and providing feedback takes too much of their time.

\section{Conclusion}

The University of Rijeka has recognized the need to keep its relevance in its surroundings, in order to increase the capacity of people and institutions for a wise use of technological development, effectively and efficiently. In this context, it was necessary to transform its own structure, processes, and programs in order to be more flexible and more responsive to changing needs in the environment (Bonk, 2009; Hanna, 2003).

We need to stress that quite some time was needed from the beginning of the process until some visible and measurable results appeared (incubation or lag phase period). Nevertheless, we need to point out that the very beginning was really building up from ground zero - the preliminary surveys in 2005 revealed that just a few academics had ever heard of e-learning tools and that for the majority of teachers the ICT in teaching was synonymous with using PowerPoint presentational tool and searching the Internet for collecting new information.

After three years of work, the results are visible, not only in the services developed and number of e-courses delivered to students, but also in some aspects of T\&L quality improvements, at least as suggested by academics in our preliminary survey. As the results indicate, blended e-learning 
offered to students helps in achieving better efficiency and efficacy of T\&L at the University; it is well accepted and well supported. The majority of teachers report on improved teaching practice (improved accessibility of course materials to students, better communication with students, fast channels to provide feedback to students), easier course management and student follow-up, better personal time management, and improved ICT literacy.

Importantly, during the process of e-learning implementation, a community of teachers using elearning tools in their teaching has been built; they are connected on one side to decision-makers and on the other to support services through the university e-learning net. A few points for getting support and networking have been established within University infrastructure: there is a faculty e-learning team and/or representative taking care of the institutional promotion and deployment of e-learning, connected to the university Committee for e-learning as a policy making body, there is the e-learning centre, which provides e-learning platform maintenance, development and technical user's support, and there is the IT Academy which assures delivery and development of education from general ICT to specialized e-learning programs. All the processes and activities within network are assured for quality control.

Our results clearly show that not only the capacity building (in terms of building "abilities of individuals and institutions to perform functions, solve problems and set and achieve goals", Selim 2004) was successful, but also that the way e-learning was implemented is in accordance with at least some of the success criteria discussed by Govindasamy (2002) and Selim (2004). These criteria were met in the first place by setting the institutionally supported implementation in which some critical parameters were controlled: dissemination of information on best practices in elearning thematically tailored to a specific institution, adequate and outcome-based education of teachers on use of e-learning tools, assured technical support for e-learning implementation, and developed mechanisms for quality control. This environment facilitated the e-learning deployment, measured with constant increase of number of e-courses offered to students. Nevertheless, we must emphasize that this initial stage of e-learning implementation almost certainly gathered teachers intrinsically interested in T\&L innovation as well as ICT literates; in this light we should expect the e-learning acceptance in the next phase of implementation grows at least at a slightly reduced rate (for reasons of joining of teachers not so ICT skilled and not so T\&L quality improvement oriented).

It is necessary also to emphasize that the university top management commitment was the key driving force in this project, both strategically via policy (and budget) channels but also through setting the scene for faculty/department/personal levels of implementation. Moreover, the initial infrastructure that has been set up for e-learning implementation seeks to sustain the collaborations and the continuously offered educational program and support for teachers - the most important factors for the success, as already discussed in literature (Deeson, 2007; White, 2007).

Although much of the effort and investing into resources is still needed, let us conclude that the report presented here could serve as a case of good practice in institutionally supported e-learning implementation model. We believe that through this approach we succeeded in building a solid institutional framework, awareness and understanding, visibility, promotion, and common language within the community, which will all hopefully serve for future progress. 


\section{References}

Aczel, J. C., Peake, S. R., \& Hardy, P. (2008). Designing capacity-building in e-learning expertise: Challenges and strategies, Computers \& Education, 50(2), 499-510.

Bates, A. W. (1999). Managing technological change: Strategies for academic leaders. San Francisco: Jossey Bass.

Bonk C. J., \& Graham, C. R. (2006). The handbook of blended learning: Global perspectives, local designs. Pfeiffer.

Bonk, C. J. (2009). The world is open: How web technology is revolutionizing education. Jossey-Bass.

Davis, H. C., \& Fill, K. (2007). Embedding blended learning in a university's teaching culture: Experiences and reflections. British Journal of Educational Technology, 38(5), 817-828.

Deeson, E. (2007). Cases on global e-learning practices: Successes and pitfalls. British Journal of Educational Technology, 38(5), 949-949(1).

Govindasamy, T. (2002). Successful implementation of e-Learning: Pedagogical considerations. The Internet and Higher Education, 4, 287-299.

Hanna, E. D. (2003). Building a leadership vision - Eleven strategic challenges for higher education. EDUCAUSE Review Magazine, 38(4), 25-34.

Selim, H.M. (2004). Critical success factors for e-learning acceptance: Confirmatory factor models. Computers \& Education, 49, 396-413.

White, S. (2007). Critical success factors for e-learning and institutional change-Some organizational perspectives on campus-wide e-learning. British Journal of Educational Technology, 38(5), 840-850.

\section{Biographies}

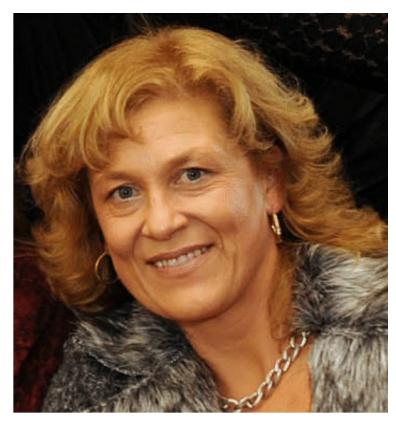

Marta Zuvic-Butoracfrom the University of Zagreb, Croatia, in the field of biophysics. For 14 years she worked as a researcher and teacher at the School of Medicine, University of Rijeka, and after completing the education for an e-learning manager (joined studies UBC Canada and CARNet Croatia) she organized and is today heading the IT Academy and E-learning centre at the University of Rijeka.

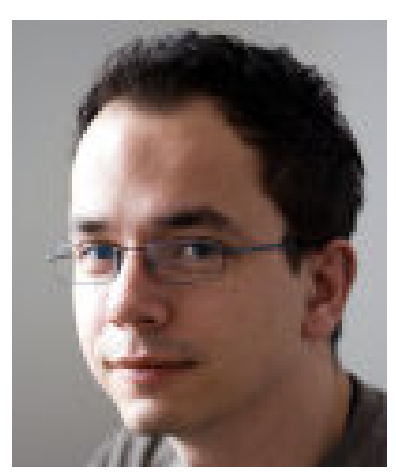

Zoran Nebic received his MEd from the University of Rijeka, Croatia. $\mathrm{He}$ is currently studying towards earning a $\mathrm{PhD}$ at the University of Ljubljana, Slovenia. After a period of working as a software engineer he was employed by the University of Rijeka where he currently works in the area of life-long learning and professional education, and teaches a course in programming. His research interests include data mining and evolutionary computing. 


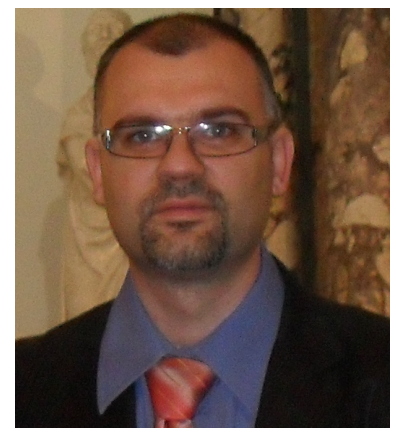

Damir Nemcanin received his MEd from the University of Rijeka, Croatia. He is currently a PhD student at the University of Zagreb. Initially he worked as software engineer and teacher of computer science at high school, currently he is working as teaching and research assistant and administrator of university e-learning system. His research interests include cloud computing, databases in cloud and implementation of e-learning in higher education.

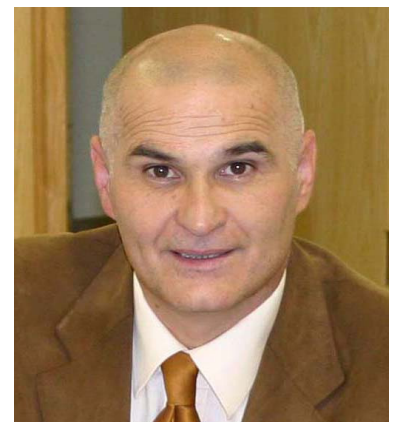

Tonci Mikac is a professor at the University of Rijeka, Croatia, where he received his $\mathrm{PhD}$ in the field of Engineering. In the past 30 years he worked in business and industrial environment as a professional and as a research scientist in many research projects. He was Dean of the Faculty of Engineering, University of Rijeka, and member of the Senate in two terms, and currently is the Vice-Rector of the University of Rijeka and Member of Croatian Academy of Technical Sciences.

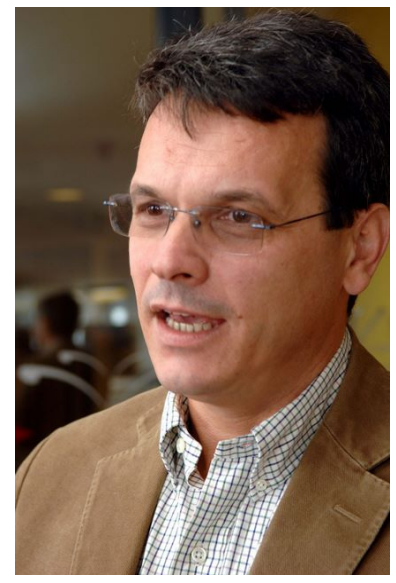

Pero Lucin, M.D., PhD is the Rector of the University of Rijeka and professor of physiology and immunology at the University of Rijeka, Faculty of Medicine. He was vice-rector of the University of Rijeka in the period 2000-2009, President of the National foundation for science, higher education and technological development of the Republic of Croatia in the period 2003-10, and Croatian negotiator for the accession with the European Union responsible for chapters on Science and Research and Education and Culture (since 2005). 